\title{
Teacher understanding and implementation of motivational strategies in ELT
}

Julie Waddington, UdG

\begin{abstract}
This article explores how teachers understand and implement motivational strategies in an ELT context. A qualitative study was carried out with 26 experienced in-service primary school teachers. The study identified initial understandings of the concept of motivation and specific ways in which teachers aim to implement motivational strategies in their classrooms. The findings verified the hypothesis that teachers' understandings of motivation are limited and do not reflect the theoretical advances made over recent decades in ELT-related motivational research. The study traced the changes in understandings resulting from a 30-hour in-service staff training programme developing a process-oriented approach to motivation. The results show that significant changes in understandings can be achieved through focused training activities, with participants expressing clear intentions to apply their new understandings to their practice in a way which will shift the emphasis from current teacher-centred approaches to more learner-sensitive environments.
\end{abstract}

\section{$\underline{\text { Introduction }}$}

Motivation is a highly complex concept, as highlighted in the introduction to the term provided in the Key Concepts feature of this journal:

Motivation is a property of the learner, but it is also a transitive concept: coaches can motivate their clients, teachers can motivate their students. Furthermore, it is dynamic and changes over time, especially in the usually long-drawn out process of language learning. Motivation is thus remarkably complex. (McDonough 2007: 369)

This introduction provides a valuable insight insofar as it locates motivation within the learner - within an ever-changing, dynamic process influenced by a multitude of factors - while simultaneously highlighting the key role that teachers play in this process. By contrast, and influenced considerably by behaviourist approaches to learning, early theories of motivation tended to locate the key to motivation externally, outside the learner, understanding it to be the teacher's task - or duty to provide the appropriate stimuli to 'motivate' their students (Williams, Mercer, \& Ryan 2016: 100-101). This view of motivation placed the teacher in a central and dominating role within the teaching/learning process: a conception that does not fit comfortably with current developments in education in general, and with the growing awareness of the need to promote learner autonomy and the learner's direct involvement in their own learning process from an early age (Ellis \& Ibrahim 2015), Understanding the concept of motivation and the way it influences the 
learning process is therefore considered vital within the teaching profession, as reflected in the revised edition of Dörnyei and Ushioda's Teaching and Researching Motivation (2011), emphasising a shift from previous thinking on motivation 'towards a more complex, more dynamic and more situated approach with a more pronounced educational relevance' (Dörnyei \& Ushioda 2011: 7). Influenced by cognitive theories of learning, this shift places the learner in the central role and suggests that the mere application of external stimuli by the teacher is not enough. Instead, the role of the teacher changes, with an emphasis on the need to develop understanding of how learners conceive their own learning process and how their thinking shapes their behaviour, before considering how they, as teachers, can facilitate or improve this process. In addition to this cognitive perspective, it becomes equally important for teachers to build awareness of their students' feelings and sensitivities, as well as their specific contexts, and to incorporate this awareness into their classroom management and organisation (Williams et al. ibid.: 102-109).

Despite the growing body of literature in this field, little work has been done to show how teachers understand the concept of motivation and how they implement it within their practice. A recent collection exploring this question highlights the increasing gap between theory and practice, arguing that teachers need comprehensible guides to help them incorporate theoretical developments in motivational studies into their own practice (Lasagabaster, Doiz, \& Sierra 2016). Ryan highlights the concern that theory and practice have tended to exist independently, emphasising that 'there is now a clear need for work that explicitly addresses their links':

As the editors of Motivation and Foreign Language Learning: from Theory to Practice observe, "The ever increasing workload of teachers leaves little time for searching through the currently abundant literature on motivation' (p. 177). And the same can be true for researchers, who are often too absorbed in theoretical complexities to explore practical classroom applications (2016: 225).

The study presented in this article is framed within this context insofar as it explores the question of how teachers understand motivation; how they implement it within their practice; and how their intentions change during the course of a staff development programme aimed at developing their understandings of the concept. Regular contact with in-service teachers led me to form the hypothesis that theory had not filtered through to practice in relation to understandings of motivation: specifically, it seemed that teachers tended to equate motivation with the use of activities that learners find 'fun' or 'enjoyable', showing limited understandings of theoretical approaches to motivation that take into account and aim to address the full spectrum of the learning process. In view of this, I decided to carry out a study with a twofold aim:

1 To test the hypothesis stated above by exploring how teachers understand motivation.

2 To observe how teachers' understandings change as a result of a staff training programme focused specifically on this concept. 


\section{The study}

\section{The training course}

After presenting an initial paper on motivation at the annual Conference on English Language Teaching organised by the Catalan Association of English Teachers (APAC), (Waddington \& El Bakouri 2016), I was asked to design and deliver an intensive 30-hour training course as part of the ongoing teacher training programme funded by the Ministry of Education. Appendix 1 provides an outline of the course offered. I decided to design the training programme in line with one author's conceptualisation and theoretical approach to motivation - the processoriented approach proposed by Dörnyei (2001) - in order to provide a suitable working model that the participants could follow during and after the training course. I considered this model fit for instructional purposes: firstly, because it was initially developed for educational applications and, secondly, because of the author's emphasis on 'comprehensiveness' (Dörnyei Ibid.: 28). An example of this is the way in which the different stages of the learning process are organised into separate components parts, thus encouraging teachers to focus on the different stages separately (see Figure 1 below).

Insert Figure 1 approx. here

Drawing attention to the different stages in this way means that specific strategies can be proposed to attend to each component (and subcomponents), with a full check-list of the corresponding motivational strategies providing a means of inspiring teachers to try out new strategies in a gradual and 'stepwise' manner, which takes full account of both the complexities of the learning process and the increasing demands made of teachers (op.cit.: 136-144). The course was therefore designed on the basis of this model as described in Appendix 2.

\section{Participants}

The study was conducted with two groups of primary school teachers enrolled on a staff-development training programme in 2014-2015 (Group 1) and 2015-2016 (Group 2). All participants were trained primary school teachers working in state schools in Catalonia as shown in Table 1.

\section{Insert Table 1 approx. here}

The profile shows a predominance of female teachers, consistent with general tendencies in the primary education profession, although Group 1 includes a higher than usual percentage of male teachers. Overall, the profile indicates high levels of experience, with between 70\% (Gp 1) and 75\% (Gp 2) having more than 6 years' experience as primary school teachers; and between $42 \%$ (Gp 2) and 45\% (Gp 1) over 10 years'. Most of the teachers participating in the study are currently teaching EFL in primary school settings in Catalonia: the only exceptions are explained in Table 1. All teachers confirm that they usually spend two hours with each of the groups they teach (two one-hour classes) during the school week, consistent with the corresponding education authority regulations and curricular guidelines. 


\section{Data collection and analysis}

In order to collect data on the participants' initial understandings of motivation, a Self-Reporting Questionnaire (SRQ) was administered prior to starting the course, which asked them to report on: 1 their reasons for enrolling on the course; 2 their expectations of it; 3 their previous experience of motivational theories or courses; 4 their views on some closed multiple choice questions on motivation; and finally, 5 the ways in which they include motivation in their current practice. After collecting the Questionnaires, I conducted a group discussion with them in an open forum which allowed them to debate some of the points at greater length. The same procedure was followed on completion of the training programme, with a Self-Reporting Questionnaire asking participants to identify motivational strategies they would like to develop in their practice. Once again this was followed by an open discussion to share views and future intentions. Direct observations of presentations made by participants during the course also provided additional data on current practice versus future intentions.

I decided to use a mixed method of data analysis, triangulating data from the selfreport questionnaires, discussion groups and observations. In the first instance, I aimed to address the first research question by analysing how teachers understand motivation and how they implement it within current practice. Analysis of the first three open questions (reasons for enrolling, expectations of course, previous experience of similar courses) offered initial qualitative data, which was complemented by the quantitative data obtained in responses to the multiple choice questions. While this analysis provided insight into teachers' initial understandings, considerably richer data was obtained from the responses given to the open-ended question asking how they promoted motivation in their current practice. In order to analyse and interpret this rich, yet complex data, and with a view to contrasting it with the data obtained at the end of the training course, I decided to use a Framework approach to quantitative data, characterised by the aim to retain a close link with the raw data, while developing a thematic analysis which prioritises the research questions (Ritchie, 2013). In the first instance, the raw data - all examples of how teachers promote motivation - was extracted from the questionnaires. These examples were then coded and grouped together into similar categories, merging some of them to avoid repetition (e.g. 'putting students in groups' merged with 'asking students to work in groups') and facilitate analysis, by turning the raw data into useful data. This data - the resulting list of examples was then compared with the checklist of strategies used to structure the training course (Dörnyei op.cit.: 136-144), and each example was matched with one of the 35 strategies proposed by Dörnyei. Interpreting the data in line with the preestablished model helped to present it in an organised and logical sequence and to highlight which component parts of the learning process were being addressed. This sequence was followed again with the data obtained in the final questionnaire asking participants which strategies they would like to develop in their practice.

\section{Findings}




\section{Initial}

With regards to the introductory questions (reasons, expectations, previous experience), despite the explicit information provided in the title and outline of the training course, most participants did not refer to motivation when explaining their reasons for enrolling. Instead, most responses referred to improving teaching practice in general, with a particular emphasis on acquiring new ideas and resources for use in their English classes. Some participants referred to motivation, but without going any further than saying that 'it is very important when teaching', or 'it is essential to achieve meaningful learning'. When motivation was mentioned, it seemed to be taken as a given and as something that did not require further clarification. Only two participants showed signs of engaging with the question of what we actually understand by motivation, with one explaining that she 'enrolled on this course to know more about motivation', and another talking about wanting to 'become more conscious about how and when to motivate pupils and how to maintain it'. With the exception of these two examples, comments displayed a general tendency to use the term motivation to relate to learning situations in which learners appear to be interested and engaged, but with little awareness of the complexities of the concept. In response to one of the multiple choice question of the SRQ asking how much time they dedicate to planning motivational activities or strategies, only 3 of the participants indicated that they spend a lot of time on them; with the majority claiming to spend some time, and 1 no time in particular.

Regarding specific ways in which they promote motivation, results of the data analysis of the open-ended responses are shown in Table 2:

Insert Table 2 approx. here

The results show that the majority of strategies reported fall into the category of Maintaining and protecting motivation, showing a particular emphasis on the use of resources or the way in which resources or activities are presented in class. The majority of the items listed under this component fall under the category 'making learning more stimulating and enjoyable', whether by 'breaking the monotony of classroom events'; 'increasing the attractiveness of tasks'; 'enlisting learners as active participants'; or 'presenting and administering tasks in a motivating way'. Only two examples given corresponded to the first component of the model (Creating the basic motivational conditions) in relation to class organisation and the benefits of working in small cooperative groups; and few examples are provided to show work on the second component (Generating Initial Motivation), beyond the need to make materials relevant for students and one interesting observation highlighting the need 'to help students create realistic learner beliefs.' Although participants indicate awareness of the need to encourage students in a general sense, no specific examples were given corresponding to the final component Encouraging positive self-evaluation.

With regard to the first objective of this study, the findings confirm the initial hypothesis by showing that EFL teachers tend to equate motivation with the use of activities that learners find 'fun' or 'enjoyable' and show limited understandings of the complexities of the concept. The discussion groups supported this further, 
highlighting a lack of awareness of current theories on motivation (only Gardner was cited as a relevant theorist) and limited awareness of pedagogically-grounded approaches to the concept.

An exception to the hypothesis is detected in relation to one of the participants in Group 1 who, unlike the other teachers, was employed as a Linguistic Support teacher assisting newly arrived immigrant children to learn the language of instruction before being able to move into mainstream classes. She was therefore unique within the sample insofar as she helps learners acquire a language which is foreign for them within the socio-cultural context in which it is the language of school instruction and in a context in which their learning of this language is vital not only academically, but also on a social, cultural and personal level. This situation has turned out to be highly relevant for this study as it has provided an alternative picture of classroom practice influenced greatly by the different learner profile that this teacher works with. The data corresponding to her initial contributions has therefore been extracted into a separate table (Table 3 ).

\section{Insert Table 3 approx. here}

An overall tendency to prioritise issues of well-being is foregrounded in the examples provided here; with an emphasis on relationship building, creating a pleasant and supportive environment, promoting the development of group cohesiveness, providing regular doses of success, and highlighting the ongoing progress made in learners' language acquisition.

\section{On completion of the training programme}

The results of the post-programme analysis showed a marked change in participants' understandings of motivation and a considerably wider scope of potential activity in terms of how they intended to develop motivational strategies in their own practice. A significant qualitative difference can be observed if we compare the initial examples provided in Table 2 with the examples shown in Table 4; indicating a more even distribution of strategies across all four of the different component parts of the process-oriented approach.

\section{Insert Table 4 approx. here}

The initial tendency to associate motivation almost exclusively with the use of attractive resources, or with the way activities are presented, underwent a significant shift. While references to activities and resources were still very much present, within the category Maintaining and protecting motivation, these were now cushioned within an overall framework taking much more account of the stages prior to this phase - Creating the basic motivational conditions and Generating initial motivation - as well as important questions related to learner self-image, perseverance and effort attribution, encompassed within the component Encouraging positive retrospective self-evaluation. With regards to this last component, no items were found matching this category in the Initial SRQs or in initial discussions. A clear shift in focus was thus observed, with participants 
having become more aware of the need to encourage learners to reflect more on their own effort and perseverance; to give more weight to effort when evaluating students' work; to give more instructive feedback; and to include learners in the evaluation process, making it more transparent and meaningful for them. Related to this point, we also find increased awareness of the need to stimulate more learner autonomy and of the potentially motivating effect of encouraging students to define their own goals and those of the class in general; to increase their expectancy of success; and to develop realistic beliefs about learning.

Data from final discussions showed that the final session of the course - in which teachers were encouraged to reflect on their own experiences as learners and focus on the importance of effort attribution and perseverance in their own successes and failures - had played a particularly important role in shifting their attention away from resources and activities towards the learning process itself. Concerning the second research question, the findings show that teachers' understandings changed considerably as a result of the staff training programme.

\section{Conclusions and implications for educational practice}

The findings indicate that intensive training courses focusing on motivation can indeed help develop teacher understandings of the concept and influence future intentions, shifting the focus from a teacher-centred approach to a more learnersensitive one. In this particular case, the structured nature of the course and use of a theoretical model designed specifically for educational application has provided an organisational framework for tackling an immensely complex concept in a manageable way, while also providing a mechanism for interpreting the rich data provided by participants.

In view of this, I would encourage researchers to conduct similar studies to verify the findings presented in this paper and to develop this emerging field of research. Firstly, however, I would like to point out some limitations of this study. In the first instance, the study is restricted to a narrow profile of participant teachers who share similar backgrounds and work in similar socio-economic contexts. The findings highlighted in Table 3 in relation to the teacher with a different profile highlight the significance of this factor. Future studies could pay more attention to this aspect, using a wider and more varied sample of participant teachers, in order to present and account for different teaching approaches. Secondly, the theoretical model used has been restricted to one author's conception of motivation. Although the decision to use one author has been justified for instructional purposes, future studies could experiment with different theoretical models, provided that due attention is paid to the comprehensiveness of the model and its ease of direct application in educational settings. The model should also facilitate the kind of quantitative data analysis procedure used in this study, which has been particularly helpful in organising the rich data obtained, helping to capture genuine viewpoints without limiting participants' responses by potentially prescriptive or biased closed-questioning techniques. 
Finally, one of the most significant shortfalls of the study is that it observes and explains changes in teachers' intentions and not in their actual practice (Guskey 1986). Future studies should develop ways to address this and develop strategies to encourage the transfer from intention to practice, promoting teachers' capacity for reinvention after the training (Sansom 2017). I am currently designing a study to explore the long-term effect of the training on the participants' teaching practice. In hindsight, it would probably have been advantageous to advise participants about the future study at the end of their training. In fact, the act of advising them would correspond to one of the specific motivational strategies included within the Creating the basic motivational conditions component of the model used in this study: Motivational strategy 2. 'Taking the students' learning very seriously: Show students that you care about their progress. Have sufficiently high expectations of what your students will achieve' (Dörnyei op.cit.: 137). Future studies would do well to incorporate this aspect into their designs. This would provide a mechanism for measuring the long-term effect of training, while also functioning as an explicit motivational strategy, encouraging teachers to put their new understandings and informed intentions into practice.

Word count including appendices: 4,257.

\section{$\underline{\text { References }}$}

Dörnyei, Z. (2001). Motivational Strategies in the Language Classroom. Cambridge: Cambridge University Press.

Dörnyei, Z. \& Ushioda, E. (2011). Teaching and Researching Motivation (2nd edition). Harlow: Longman.

Ellis, G. \& Ibrahim, N. (2015). Teaching children how to learn. Surrey: Delta Publishing. Guskey, T. R: 1986. 'Staff Development and the Process of Teacher Change'. Educational Researcher. Vol. 15. No. 5. P. 5-12.

Lasagabaster, D., Doiz, A., Sierra, J. M. (eds.). 2016. Motivation and Foreign Language Learning: From theory to practice. Amsterdam: John Benjamins Publishing.

McDonough. 2007 'Motivation in ELT'. ELT Journal, Key Concepts in ELT, 61 (4): 369-371.

Mercer, S. 2016. 'International Perspectives on Motivation: Language Learning and Professional Challenges'. ELT Journal, 70 (2): 227-230.

Ritchie, J. et al. (2013). Qualitative Research Practice, London: SAGE.

Ryan, S. 2016. 'Motivation and Foreign Language Learning: From Theory to Practice'. ELT Journal, 70 (2): 225-227.

Sansom, D. W. 2017. 'Reinvention of classroom practice innovations'. ELT Journal. ccw116.

Waddington, J. \& El Bakouri, Y. (2016). 'Fictitious Emails and Their Use as a Motivational Strategy'. APAC ELT Journal, Jan 2016, Vol 82.

Williams, M., Mercer, S., \& Ryan, S. 2016. Exploring Psychology in Language Learning and Teaching. Oxford: Oxford University Press.

\section{The author}


Julie Waddington teaches at the University of Girona (Catalonia) in the Faculty of Education and Psychology, drawing on her previous practical experience as a fulltime English language teacher (UK and Spain). Prior to this, she taught at Manchester Metropolitan University, England, where she completed her PhD in Literary Studies and Critical Theory (2007). Her current research interests focus on learner identity and the development of learner-centred practices in teacher training.

Email: julie.waddington@udg.edu

\section{Appendix 1}

Description of Training Course (part of in-service ongoing training programme)

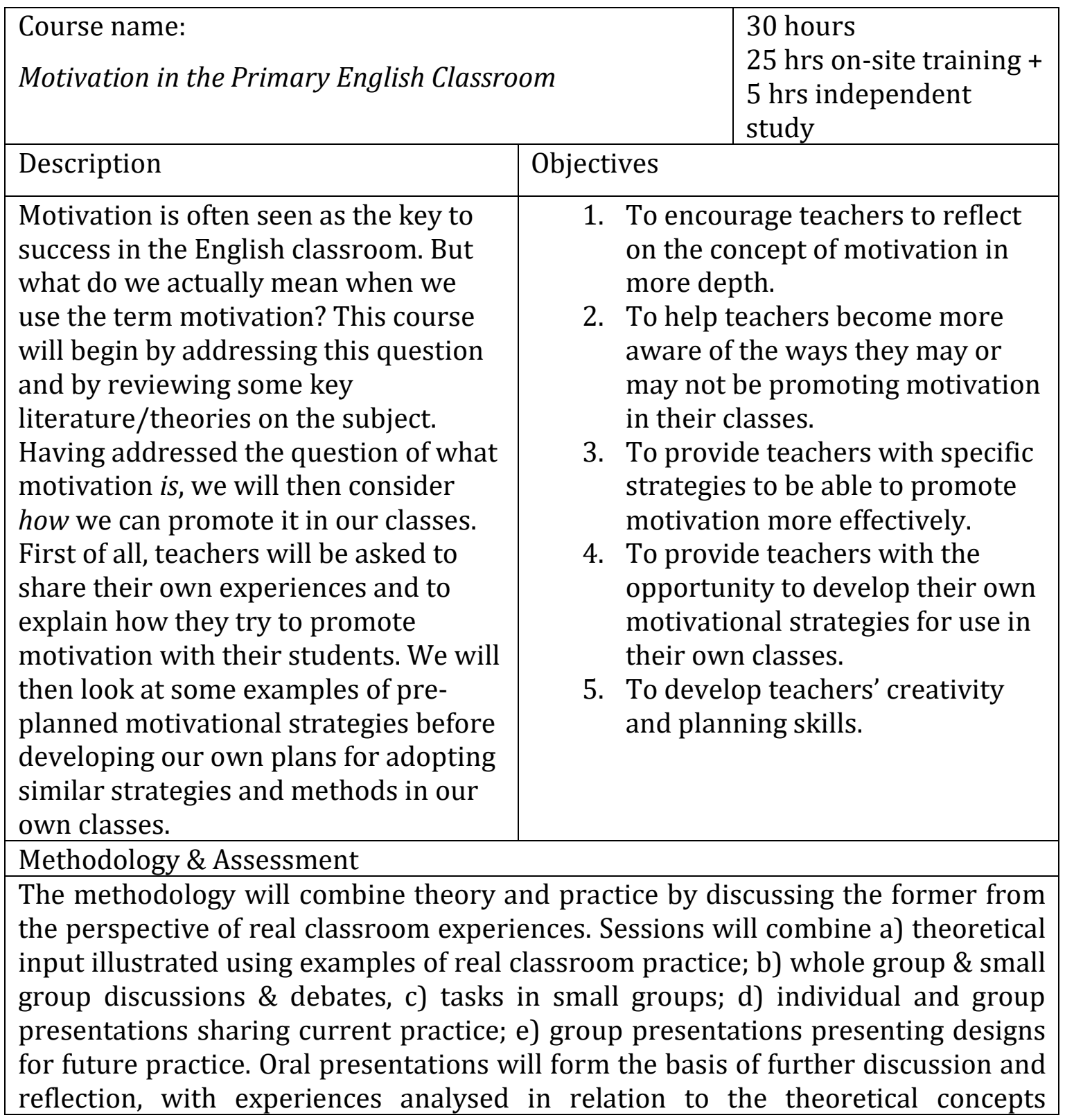


discussed. Participants will be assessed on the basis of their active participation in the course and their completion of all set tasks.

The course details shown above were openly available to teachers prior to enrolment on the Catalan Government's Ministry of Education website.

\section{Appendix 2}

Motivation in the Primary English Classroom

An intensive one-week course for Primary English School Teachers

$9 h-14 h$ ( 5 hours +5 hours independent study)

Overview of session content:

\section{Session 1: Introductions and course presentation}

Introductions/icebreakers/getting to know you activities. Presentation of course: structure, content, objectives. Initial Self-Reporting Questionnaire (on current practice). Discussion/reflection on current views and perspectives on motivation in the English classroom. Presentation of key approaches to motivation (through reading activity in small groups followed by presentations to share different content with whole group). Discussion of relevance of different approaches to participants' practice. Presentation of process-oriented model from Motivational strategies in the language classroom to be explored during course (Dörnyei, 2001). Signposting: Explanation that next 4 sessions based on process-oriented approach, focusing on one stage of process in each session and using the stepwise approach (list of 35 specific strategies with tick-boxes to indicate if part of teacher's practice already or to indicate intention to try out) to provide an organising framework.

\section{Session 2 Creating the basic motivational conditions}

Warmer activity. Pairwork: reading through Stepwise approach checklist, identifying if and how strategies form part of current practice. Group sharing \& discussion. Presentation by trainer showing examples in which strategies corresponding to the component are put into practice effectively. Small group work devising plans to incorporate new strategies in own practice. Presentation of plans, whole group reflection \& discussion.

\section{Session 3 Generating initial motivation}

Warmer activity. Pairwork: checking homework (same activity as session 2 reading through Stepwise approach checklist, identifying if and how strategies form part of current practice - but carried out individually before the session). Sharing with whole group \& discussion. Presentation by trainer showing examples in which strategies corresponding to the component are put into practice effectively. Small group work devising plans to incorporate new strategies in own practice. Presentation of plans, whole group reflection \& discussion.

Session 4 Maintaining and protecting motivation 
Warmer activity. Presentation by trainer showing examples in which strategies corresponding to the component are put into practice effectively. Small group work: pooling together of homework followed by preparation of brief presentations to illustrate different strategies used. Group presentations, feedback \& discussion.

Session 5 Encouraging positive self-evaluation

Teachers as learners: consideration of last component from teachers' perspectives as learners. Reflection on what has/has not motivated them as learners in the past. Interactive activities to encourage self-reflection on past experiences and to highlight attributional perspective (what they attribute past successes and failures to). Special attention to role of effort and perseverance in own experiences and reflection on how to promote this effort attribution in own learners/classrooms. Reflection on current practice in relation to feedback and assessment. Design of plans to develop practice in this regard in line with Stepwise strategy checklist. Final Self-Reporting Questionnaire (intentions regarding future practice). Final discussion and reflection on experience. 


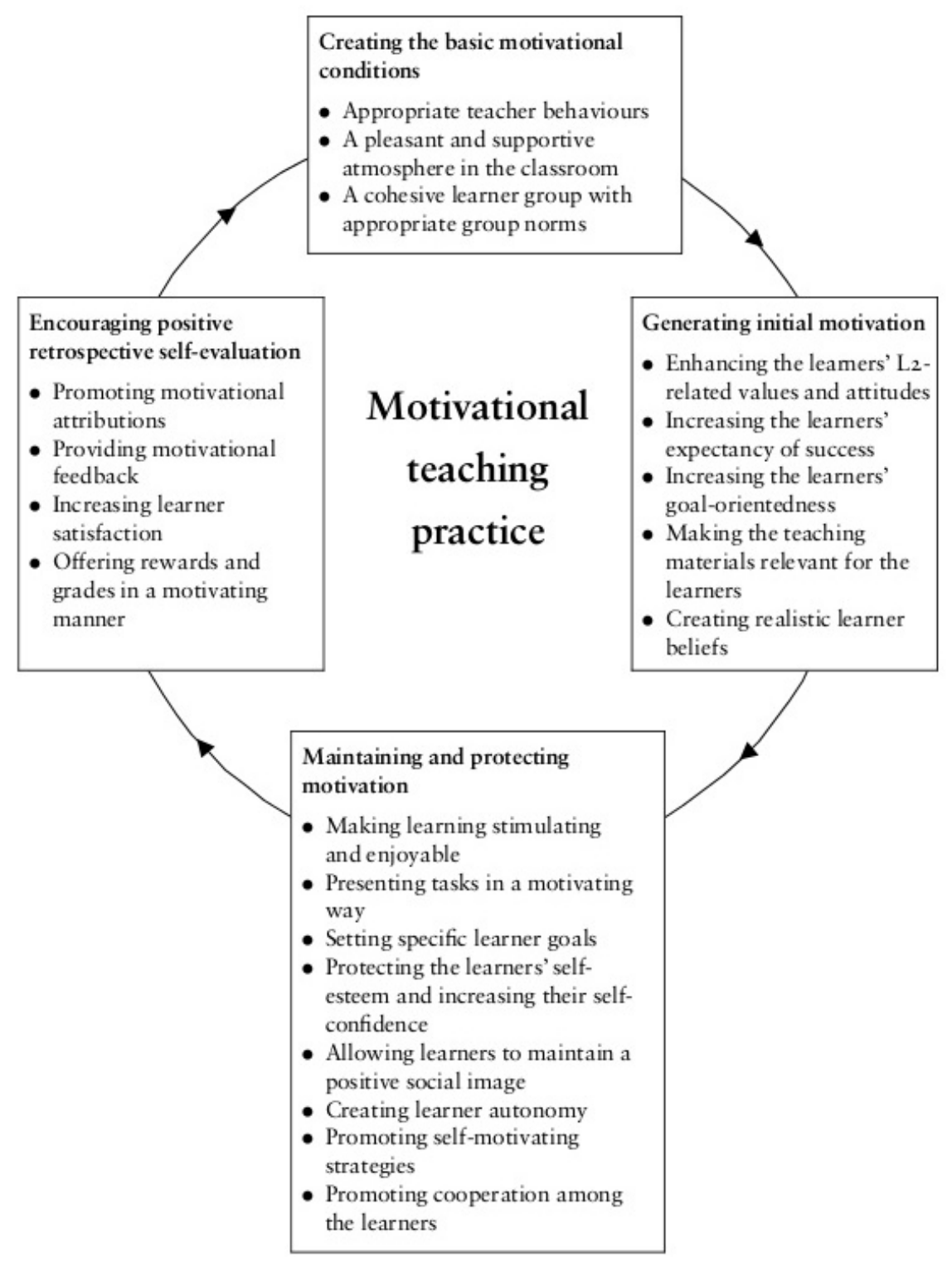

Figure 1. The components of a process-oriented approach to motivational teaching in the L2 classroom (Dörnyei 2001: 29). Source: reproduced with kind permission of author.

Table 1

Group 1. 2014-2015

\begin{tabular}{|c|c|c|c|c|c|c|c|}
\hline $\begin{array}{l}\text { No. of } \\
\text { participants }\end{array}$ & Male & Female & $\begin{array}{l}\text { 1-5 years } \\
\text { teaching } \\
\text { experience }\end{array}$ & $\begin{array}{l}\text { 6-10 years } \\
\text { teaching } \\
\text { experience }\end{array}$ & $\begin{array}{l}10+ \\
\text { teaching } \\
\text { experience }\end{array}$ & $\begin{array}{l}\text { Currently } \\
\text { teaching } \\
\text { EFL }\end{array}$ & $\begin{array}{l}\text { Not } \\
\text { teaching } \\
\text { EFL }\end{array}$ \\
\hline 13 & 5 & 8 & 4 & 3 & 6 & 11 & 2* \\
\hline
\end{tabular}

*One specialised in EFL during his BEd in Primary Education, but is now working as a general primary teacher with no EFL responsibilities. 
The other also specialised in EFL but has been working within a Linguistic Support Class (LSC) for immigrant children in her primary school, providing them with language support in the language of instruction of the school/country (Catalan) to help them make the transition to mainstream classes.

Table 2. General profile of participants

\begin{tabular}{|l|l|l|l|l|l|l|l|}
\hline \multicolumn{2}{|l|}{ Group 2. 2015-2016 } \\
\hline No. of & Male & Female & $1-5$ years & $6-10$ years & $10+$ & Currently & Not \\
& & & teaching & teaching & teaching & teaching & teaching \\
\hline 12 & 2 & 10 & 3 & 4 & 5 & 11 & $1 *$ \\
\hline $\begin{array}{l}* 12 \text { years' general teaching practice wants to learn EFL techniques 'in case' the } \\
\text { opportunity arises to teach English. }\end{array}$ \\
\hline
\end{tabular}

Table 3. Initial examples of how participants implement motivational strategies in class

\section{Creating the basic motivational conditions}

6. Promote the development of group cohesiveness.

Changing the structure/organisation of the class

2.Generating initial motivation

Working in small groups

\begin{tabular}{|l|l|}
\hline $\begin{array}{l}\text { 15. Make the curriculum and the teaching } \\
\text { materials relevant to the students. }\end{array}$ & Asking or talking about students' lives \\
\cline { 2 - 2 } & Knowing children's interests \\
\cline { 2 - 2 } & Adapting some activities to pupils' interests \\
& $\begin{array}{l}\text { Identifying their interests and working on } \\
\text { them }\end{array}$ \\
\cline { 2 - 2 } & Looking for interesting material \\
\hline 16. Help to create realistic learner beliefs. & Asking pupils about their expectations \\
\hline \multirow{2}{*}{ 3. Maintaining and protecting motivation } & \\
\hline $\begin{array}{l}\text { 17. Make learning more stimulating and } \\
\text { enjoyable by breaking the monotony of } \\
\text { classroom events. }\end{array}$ & Using varied and short exercises \\
\cline { 2 - 2 } & Surprising them \\
\cline { 2 - 2 } & Roleplays to practice speaking \\
\cline { 2 - 2 } & $\begin{array}{l}\text { Using music: to relax pupils before they } \\
\text { begin a task or as background music while } \\
\text { they carry out a task }\end{array}$ \\
\hline $\begin{array}{l}\text { 18. Make learning stimulating and enjoyable } \\
\text { for the learner by increasing the } \\
\text { attractiveness of the tasks. }\end{array}$ & Playing games \\
\cline { 2 - 2 } & Punctuation quizzes in small groups \\
\cline { 2 - 2 } & Singing songs \\
\hline
\end{tabular}




\begin{tabular}{|c|c|}
\hline & $\begin{array}{l}\text { Using attractive materials: flashcards, story } \\
\text { cards, interactive songs, videos, etc. }\end{array}$ \\
\hline & Using visuals \\
\hline \multirow[t]{3}{*}{$\begin{array}{l}\text { 19. Make learning stimulating and enjoyable } \\
\text { for the learners by enlisting them as active } \\
\text { task participants. }\end{array}$} & $\begin{array}{l}\text { Moving around the class and introducing } \\
\text { vocabulary through TPR activities } \\
\text { Acting-out/performing at the end of a task }\end{array}$ \\
\hline & Performing songs and plays \\
\hline & Using interactive digital resources \\
\hline \multirow[t]{4}{*}{$\begin{array}{l}\text { 20. Present and administer tasks in a } \\
\text { motivating way. }\end{array}$} & $\begin{array}{l}\text { Using interactive board and internet } \\
\text { resources }\end{array}$ \\
\hline & Telling stories \\
\hline & Using digital resources \\
\hline & $\begin{array}{l}\text { Using tone of voice and gestures (teacher) } \\
\text { and engaging pupils to foster their curiosity } \\
\text { and willingness to learn }\end{array}$ \\
\hline $\begin{array}{l}\text { 24. Build your learners' confidence by } \\
\text { providing regular encouragement. }\end{array}$ & $\begin{array}{l}\text { Using encouraging expressions (Well done, } \\
\text { Nice try, etc.) }\end{array}$ \\
\hline
\end{tabular}

Table 4. Initial examples of how the LSC teacher implements motivational strategies in class

\begin{tabular}{|c|c|}
\hline \multicolumn{2}{|l|}{ 1.Creating the basic motivational conditions } \\
\hline \multirow[t]{3}{*}{$\begin{array}{l}\text { 3. Develop a personal relationship with your } \\
\text { students. }\end{array}$} & $\begin{array}{l}\text { Leaving my problems out of the classroom } \\
\text { and appearing motivated in front of the } \\
\text { children }\end{array}$ \\
\hline & $\begin{array}{l}\text { If they don't feel right for something I can } \\
\text { solve, then solve it (for instance, giving them } \\
\text { some biscuits if they haven't had breakfast) }\end{array}$ \\
\hline & $\begin{array}{l}\text { Receiving them one by one and asking how } \\
\text { they feel that morning }\end{array}$ \\
\hline $\begin{array}{l}\text { 5. Create a pleasant and supportive } \\
\text { atmosphere in the classroom. }{ }^{*}\end{array}$ & $\begin{array}{l}\text { Showing class as a pleasant place where } \\
\text { children feel comfortable }\end{array}$ \\
\hline $\begin{array}{l}\text { 6. Promote the development of group } \\
\text { cohesiveness. }\end{array}$ & Trying to make all children feel involved \\
\hline \multicolumn{2}{|l|}{ 2.Generating initial motivation } \\
\hline $\begin{array}{l}\text { 13. Increase the students' expectancy of } \\
\text { success in particular tasks and in learning in } \\
\text { general.* }\end{array}$ & $\begin{array}{l}\text { Explaining at the beginning of the class what } \\
\text { we are going to do and telling them how } \\
\text { long each activity will take }\end{array}$ \\
\hline \multicolumn{2}{|l|}{ 3. Maintaining and protecting motivation } \\
\hline $\begin{array}{l}\text { 17. Make learning more stimulating and } \\
\text { enjoyable by breaking the monotony of } \\
\text { classroom events. }\end{array}$ & $\begin{array}{l}\text { Providing a wide variety of activities in the } 4 \\
\text { language skills }\end{array}$ \\
\hline
\end{tabular}


23. Provide learners with regular experiences of success. Table 5. Examples of how participants intend to implement motivational strategies in future practice

\section{Creating the basic motivational conditions}

5. Create a pleasant and supportive atmosphere in the classroom.

6. Promote the development of group

\section{Generating initial motivation}

13. Increase the students' expectancy of success in particular tasks and in learning in general

14. Increase your students' goalorientedness by formulating explicit class goals accepted by them.

15. Make the curriculum and the teaching materials relevant to the students.

16. Help to create realistic learner beliefs.

\section{Maintaining and protecting motivation}

Increasing students' expectancy of success

Making the children participate more in the goals of the class Helping students define goals Making materials significant for pupils

Helping students to have more realistic beliefs about learning

Helping students decide their own

expectations cooperation
18. Make learning stimulating and enjoyable for the learner by increasing the attractiveness of the tasks.

20. Present and administer tasks in a motivating way.

20. Present and administer tasks in a motivating way (Explain the purpose and utility of a task).

21. Encourage learners to select specific, short-term goals for themselves.

29. Increase student motivation by actively promoting learner autonomy.
Using ICT, visual materials and songs to capture attention and maintain motivation

Presenting material in an attractive way

Telling pupils the purpose of activities (nuance introduced; not just in an attractive way but in a purposeful way)

Setting challenges and goals

Helping students define their goals better and to decide their own expectations in learning

Trying to achieve their goals, not only mine Increasing students' goals and help them set individual goals

Creating learner autonomy

4. Encouraging positive self-evaluation 


\begin{tabular}{|l|l|}
\hline $\begin{array}{l}\text { 31. Promote effort attributions in your } \\
\text { students. }\end{array}$ & $\begin{array}{l}\text { Focusing students attention more on the } \\
\text { effort they make }\end{array}$ \\
\hline $\begin{array}{l}\text { 32. Provide students with positive information } \\
\text { feedback }\end{array}$ & Giving more feedback \\
\hline $\begin{array}{l}\text { 35. Use grades in a motivating manner, } \\
\text { reducing as much as possible their } \\
\text { demotivating impact. (Make sure that grades } \\
\text { also reflect effort...) }\end{array}$ & $\begin{array}{l}\text { Focusing more on the effort they make } \\
\text { (when evaluating) }\end{array}$ \\
\cline { 2 - 2 } & Telling learners how they are evaluated \\
\hline
\end{tabular}

